\title{
Spatio-temporal analysis of vegetation variation in the Jinghe River Basin
}
Dong Fan ${ }^{1, a}$, Xiaotian Chen ${ }^{2, b}$, Yaolin $\mathrm{Li}^{3, \mathrm{c}}$, Kai Du ${ }^{4, \mathrm{~d}}$, Shufang Liu ${ }^{5, \mathrm{e}}$, Suzhen Dang ${ }^{6, f}$, Peng Guo ${ }^{7, g}$, and Guotao Dong ${ }^{8, h^{*}}$

${ }^{1}$ Henan Polytechnic University, Shiji Road 2001, Jiaozuo, 454000, China ; Yellow River Institute of Hydraulic Research, Shunhe Road 45, Zhengzhou, 450003, China

${ }^{2}$ Yellow River Institute of Hydraulic Research, Shunhe Road 45, Zhengzhou, 450003, China

${ }^{3}$ Xifeng Soil and Water Conservation Experiment Station, South Street 268, Qingyang, 745000, China

${ }^{4}$ Yellow River Institute of Hydraulic Research, Shunhe Road 45, Zhengzhou, 450003, China

${ }^{5}$ Yellow River Institute of Hydraulic Research, Shunhe Road 45, Zhengzhou, 450003, China

${ }^{6}$ Yellow River Institute of Hydraulic Research, Shunhe Road 45, Zhengzhou, 450003, China

${ }^{7}$ Henan Institute of Meteorological Sciences, Zhengzhou 450003, China

${ }^{8}$ Yellow River Institute of Hydraulic Research, Shunhe Road 45, Zhengzhou, 450003, China

a2210225173@ qq.com, ${ }^{\mathrm{b}}$ chenxiaotian@ hky.yrcc.gov.cn, ${ }^{\mathrm{c}} 576833126 @$ qq.com, ${ }^{\mathrm{d}}$ dukai@ hky. yrcc.gov. cn, ${ }^{e}$ liushufang@ hky.yrcc.gov.cn, ${ }^{\dagger}$ dangsuzhen @ hky.yrcc.gov.cn,

g154863924@ qq.com, ${ }^{\text {h }}$ dongguotao@ hky.yrcc.gov.cn

* corresponding author

Keywords: Vegetation variation, NDVI, MODIS, Jinhe River Basin.

Abstract.Vegetation is the main indicator for the state and performance of the ecological environment change. In this study, we analyzed the spatio-temporal of vegetation variation in the Jinghe River Basin. MODIS NDVI (MOD13A2) data were adopted to monitor the dynamic changes. ArcGIS and ENVI software were used to analyze the NDVI. The results show that all monthly NDVI values in the study area are between 0.20 and 0.55 , and max values of vegetation NDVI are mainly distributed in eastern and western mountains and the southeastern areas. NDVI value increases month by month since February, and reaches peak in August and then decline quickly since October. Vegetation variation presents a fluctuating increasing trend in the past decade.

\section{Introduction}

Vegetation is a general term for the plant community, as important components of the ecological cycle, can maintain the ecological environment. Vegetation is the main indicator for the ecological environment change which is important to global energy circulation and biogeochemical circulation of substances ${ }^{[1]}$. Vegetation coverage corresponds to the complement to unity of the gap fraction at nadir direction and is related with the partition between soil and vegetation contribution for emissivity and temperature, which is a critical variable for describing land surface processes and surface parameterization schemes used for climate and weather forecasting ${ }^{[2]}$. Vegetation coverage couples natural environmental changes and human activities, and is an essential index to describe the ecological system ${ }^{[3]}$. Therefore, monitoring vegetation variation has a great significance for ecology and environment, and a wide range of vegetation coverage estimation had become a foundation in establishing global and regional climate and hydrological models ${ }^{[4]}$. Vegetation coverage monitoring based on remote sensing had been developed quickly ${ }^{[5]}$. Normalized difference vegetation index (NDVI) reflecting characteristics of plant growth, vegetation coverage and biomass, is used as an 
indicator to monitor vegetation changes. NDVI is the most widely used vegetation index due to their simplicity, ease of application, and wide-spread familiarity.

Jinhe River Basin is located in Loess plateau, where had been influenced by the Grain for Green Project (GGP), which initiated in 1999. The GGP had grown more forests and shifted from degraded wasteland, and farmland to healthier manmade forests and grassland, which would promote restoration of degraded landscape ${ }^{[6]}$. The project had great potential to improve vegetation coverage of the Loess plateau ${ }^{[7]}$.To understand the effect of GGP on vegetation variation in the Jinhe River Basin, the VC vegetation coverage will been investigated. The primary objective of this study is to analyze long term vegetation dynamics in Jinghe River basin based on the NDVI data.

\section{Study area}

Jinghe River basin is located in the middle reaches of the Yellow River region, including Shaanxi-Gansu-Ningxia provinces. The region lies within latitudes within $105^{\circ} 49^{\prime} \sim 108^{\circ} 58^{\prime}$ E and $34^{\circ} 14^{\prime} \sim 38^{\circ} 10^{\prime} \mathrm{N}$. The area of basin is $45421 \mathrm{~km}^{2}$. Jinghe River basin is deep in the landscape patterns of ridge, plateau, hilly and loess hilly. Northern area is loess hilly region, central area is loess plateau gully area, southwestern area is mountain-forest area and southeastern area is mountain area ${ }^{[8]}$. The terrain is high in the northwest and low in the southeast, generally sloping from east, north and west to south. Primary land use types are agricultural land, forest, grassland, and bush, which are accounting for more than $90 \%$ (Fig.1). Primary soils are loessal soil, heilu soil, cinnamon soil, and alluvial soil. Climate belongs to typical temperate continental climate. Annual rainfall is 390-560 mm. Temperature ranges from high in the south to low in the north. Annual mean temperature is $8-13^{\circ} \mathrm{C}$.
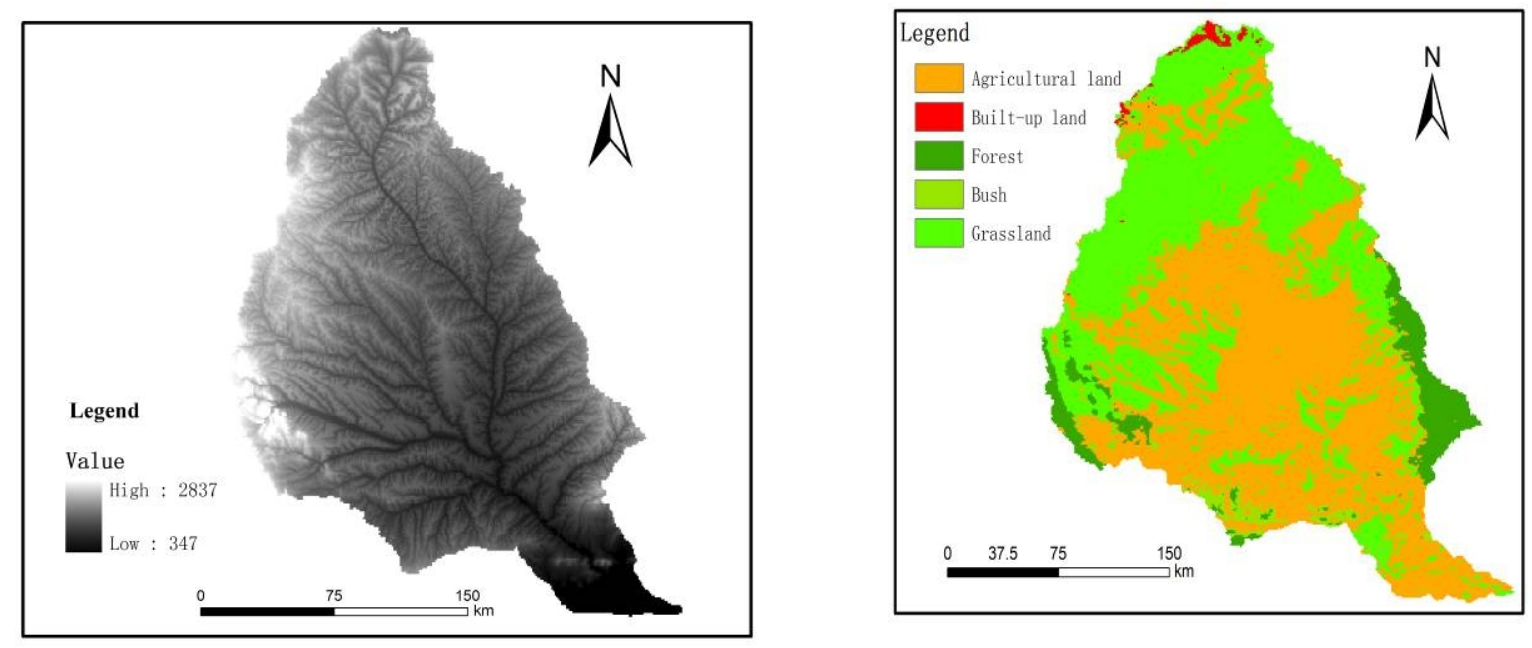

Fig.1 DEM and land use in the Jinghe River basin

\section{Materials and methods}

NASA MODIS NDVI (MOD13A2) data were sourced from the MODIS vegetation index product data on the website of the NASA (http://modis.gsfc.nasa.gov/). The data collected from February 2001 to December 2010, with a spatial resolution of $1 \mathrm{~km}$, and a temporal time resolution of 16 days. MODIS NDVI data were obtained with certain processes, such as map projection transformation, re-sampling, data format conversion and image clipping on the original MODIS NDVI image by study area mask. The NDVI data sets were utilized the Maximum Value Composite (MVC) algorithm to obtain a higher percentage of clear-sky data. Remote sensing data process and analysis were performed using ArcGIS 10.0 and ENVI 4.4 image processing software. All statistical analyses were performed using Microsoft Excel 2007. 


\section{Results}

Monthly and interanmual variation of NDVI values from 2001 to 2010 are shown in Fig. 2. All monthly NDVI values in the study area are greater than 0.20 and less than 0.55 , which indicates medium vegetation coverage in the Jinghe River basin. NDVI change presents a unimodal distribution. NDVI value increases month by month since February, peak is reached in August, and then decline quickly since October. NDVI presents a fluctuating increasing trend in the past decade with minimum annual mean value in 2001 and maximum value in 2010, which indicates that vegetation coverage is increased in the Jinghe River basin since 2001.

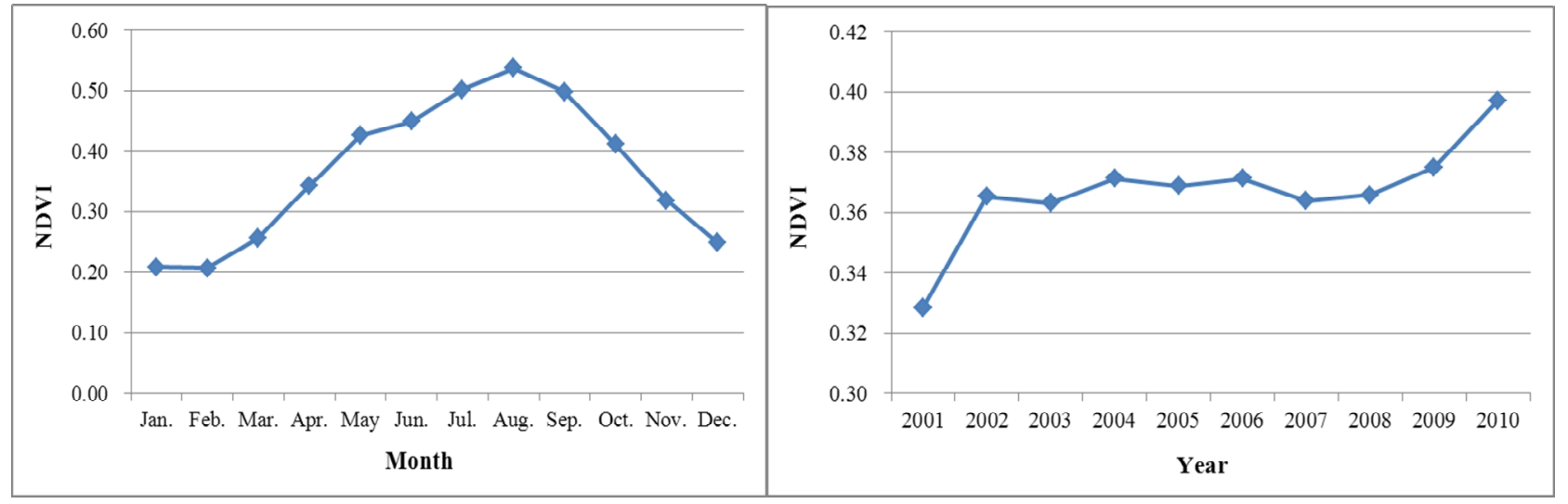

Fig.2 Monthly and interanmual variation of NDVI values from 2001to 2010

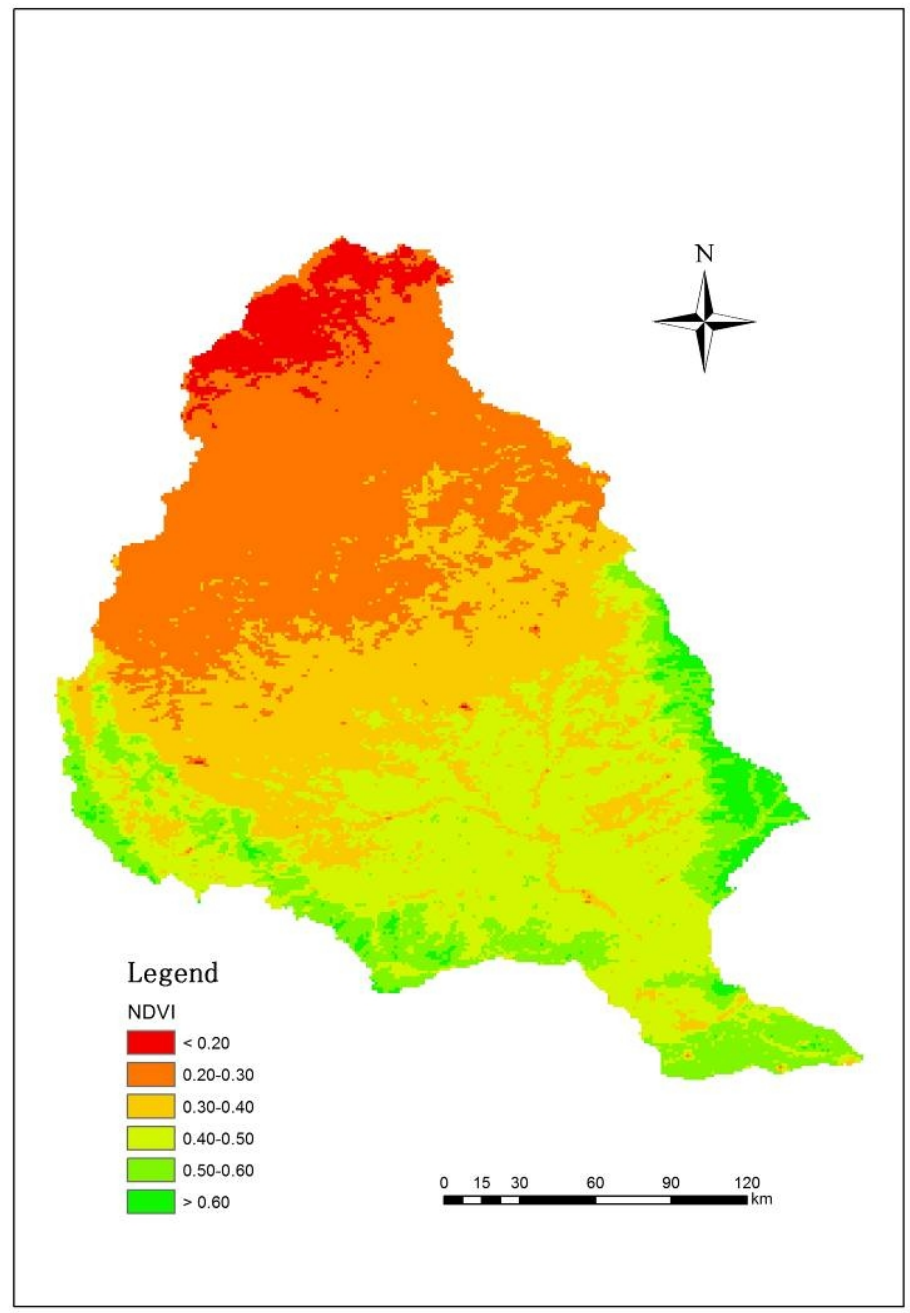

Fig.3 spatial distribution of annual mean NDVI value from 2001-2010 
Fig. 3 shows spatial distribution of annual mean NDVI value from 2001-2010. The max values of vegetation NDVI are mainly distributed in eastern and western mountains and the southeastern areas. Spatial distribution patterns indicated that NDVI is higher in lower latitudes and mountainous areas than in higher latitudes and plains. The topography and land cover are important factors of influencing vegetation NDVI distribution.

\section{Conclusions}

The spatio-temporal of vegetation variation in the Jinghe River Basin were analyzed. NDVI data were adopted to monitor the dynamic changes. The results show that all monthly NDVI values are between 0.20 and 0.55 , and max values of vegetation NDVI are mainly distributed in eastern and western mountains and the southeastern areas. NDVI value increases since February, and reaches peak in August and then decline quickly since October. Vegetation variation presents a fluctuating increasing trend in the past decade.

\section{Acknowledgements}

This study was financially supported by the National Natural Science Foundation of China (Grant No.41301496, 91325201, 41301030), the Governmental public industry research special funds for projects (201401031), and Meteorological Department Program of Henan Province (201509). Furthermore, the authors thank the anonymous reviewers for their helpful and constructive comments.

\section{References}

[1] G.J. Niemi and M.E. McDonald: Application of Ecological Indicators, Annual Review of Ecology, Evolution, and Systematics, Vol. 35(2004), p.89-111

[2] F. Sini, G. Boni, and D. Entekhabi: Measurements of Hydrological Variables from Satellite: Application to Mediterranean Regions, Hydrological Modelling and the Water Cycle, Vol. 63(2008), P. 93-113

[3] P.J. Sellers, D.A. Randall, G.J. Collatz, J.A. Berry, C.B. Field, D.A Dazlich., C. Zhang, G.D. Collelo, and L. Bounoua: A Revised Land Surface Parameterization (SiB2) for Atmospheric GCMS, Part I: Model Formulation. Journal of Climate, Vol. 9(1996), p.676-705

[4] J.M. Chen: Spatial Scaling of a Remotely Sensed Surface Parameter by Contexture, Remote Sensing of Environment, Vol. 69(1999), p.30-42

[5] S.L. Liang, X.W. Li, J.D. Wang: Advanced Remote Sensing: Terrestrial Information Extraction and Applications (Elsevler's Science\&Technology Academic Press, Kidlington, UK 2012)

[6] S. Cao, C. Xu, L. Chen, and X. Wang: Attitudes of farmers in China's northern Shaanxi Province towards the land-use changes required under the Grain for Green Project, and implications for the project's success, Land Use Policy, Vol. 26(2008), p.1182-1194

[7] D. Zhou, S. Zhao, and C Zhu: (2012). The Grain for Green Project induced land cover change in the Loess Plateau: a case study with Ansai County, Shanxi Province, China, Ecological Indicators, Vol. 23(2012), p.88-94

[8] G.T. Dong, S.Z. Dang, H.M. He, X.H. Jiang, and W.G. Zhang: Monitoring of Soil Moisture Based on Land Surface Temperature and Vegetation Index Feature Space in the Jinghe Watershed, South-to-North Water Transfers and Water Science \& Technology Vol. 12 (2014), p.11-15 